\title{
Science suffers in rocket explosion
}

Earth-viewing satellites and meteor camera among experiments lost on launch to space station.

\section{Alexandra Witze}

29 October 2014

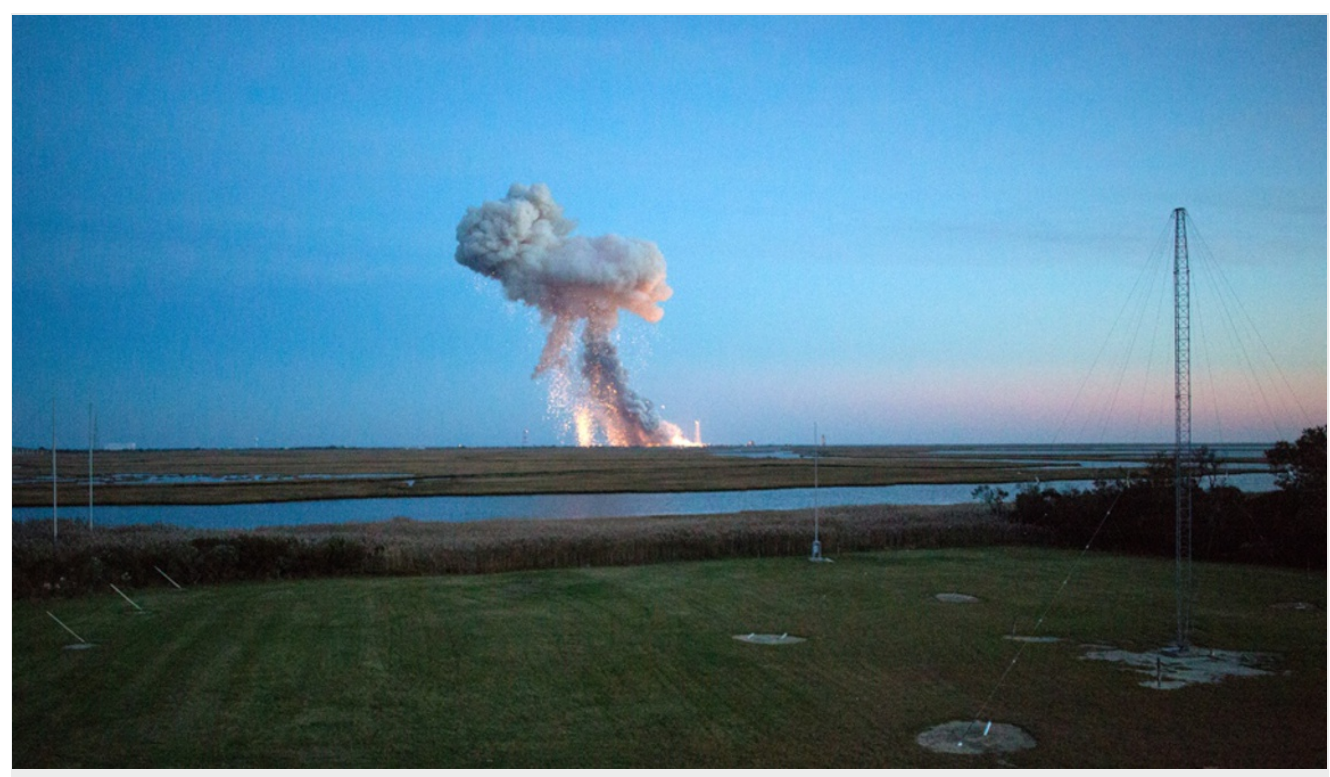

Joel Kowsky/NASA/Getty

The Antares rocket experienced a catastrophic failure just after lift-off from Wallops Island, Virginia.

When a commercial rocket exploded above a Virginia launch pad on 28 October, it also blew up carefully orchestrated plans for sending science experiments to the International Space Station.

Orbital Sciences in Dulles, Virginia, which flew the failed Antares rocket, is one of just two private suppliers with a NASA contract to fly cargo to the space station. The company will stop flying for at least three months, and possibly much longer, while investigators figure out the cause of the accident and Orbital fixes the problem. The lost delivery was the third of eight flights planned under a US\$1.9billion contract between Orbital and NASA; the fourth would have taken place next spring.

That leaves researchers who had planned to send payloads on the company's future flights without a ride to space for the time being. The accident comes as NASA was ramping up research in the part of the space station designated as a US national laboratory.

No one was hurt in the accident, and, in most cases, backup versions of the experiments will eventually be able to fly. But with programme managers now frantically reshuffling flight manifests, the challenge will be getting a spot on future launches.

"We're essentially in a bit of a bottleneck," says Abby Dickes, a spokeswoman for NanoRacks, a company in Webster, Texas, that organizes payloads for space flight.

Roughly one-third of Orbital's cargo load, or about 730 kilogrammes, was scientific equipment. That included the Arkyd 3 miniature satellite built by Planetary Resources, an asteroid-mining company in Redmond, Washington. Arkyd 3 was an early version of a space telescope the company aims to use to search for asteroids to mine for valuable deposits. A second version is already under construction and will be ready for launch next year, says company president Chris Lewicki. "We'd have loved to have celebrated, but this is space and space is inherently risky," he says.

Also on board was the Meteor experiment developed at the Chiba Institute of Technology in Japan. It was "shocking to see the rocket explode", says project manager Tomoko Arai, who was at Wallops for the launch. Meteor would have been the first space experiment to use a high-definition video camera to study the brightness and properties of dust during major meteor showers. Arai says that the researchers built a backup camera and plan to fly it as soon as they can find a spot for it. 
Perhaps the biggest science customer by numbers aboard the Orbital flight was Planet Labs, a company in San Francisco, California, that uses a constellation of small satellites to image Earth constantly. The satellites are released into orbit from the space station. Planet Labs has already launched 71 satellites for its fleet - although deployment problems have kept some of them on the space station — and would have delivered 26 more aboard the failed Orbital flight.

Other small satellites lost aboard the flight include one carrying a radiometer to measure atmospheric water vapour, from the University of Texas at Austin and NASA's Jet Propulsion Laboratory in Pasadena, California, and one to gather information on how satellites break up as they de-orbit, from the company GomSpace in Aalborg, Denmark. Student experiments also vanished, including one to grow pea shoots to feed astronauts.

\section{Shocks and setbacks}

The explosion caused serious damage to the launch pad at Wallops Island, Virginia — the only location from which Orbital is certified to launch its Antares rocket, says Frank Culbertson, the company's executive vice-president and a former NASA astronaut. "We will come back to Wallops as soon as we can, and we will fly again safely," he says.

NASA and Orbital have launched a joint investigation into the cause of the explosion, along with the Federal Aviation Administration. Early speculation about the cause has centred on the engines that constitute the rocket's first stage, which Orbital's supplier purchased and modified from a Russian stockpile that dates back to the 1960s. A test of a similar engine failed in May, although Culbertson says that the design has been "quite proven by testing".

The six astronauts aboard the station have enough supplies even if no cargo ships from any source were to arrive for another six months, says Michael Suffredini, the space station programme manager for NASA in Houston. But Russia's Progress resupply ships continue to fly — one launched less than a day after the Antares accident from the Baikonur Cosmodrome in Kazakhstan and docked with the station hours later. Orbital's rival in the US commercial market, SpaceX of Hawthorne, California, has a cargo supply run scheduled on or after 9 December. Japan's H-II Transfer Vehicle (HTV) ships are also able to supply the station.

The cargo for the December SpaceX mission is set, but SpaceX missions after that one might be able to accommodate some payloads that would have flown with Orbital. Other options including putting science payloads aboard the Progress vehicles or on Japan's HTV ships.

Rescheduling everything will take a lot of work. "Nobody likes to see a rocket blow up on a launch pad," says Dante Lauretta, a planetary scientist at the University of Arizona in Tucson.

Nature | doi:10.1038/nature.2014.16247 